\title{
Accuracy of definitive casts using 4 implant-level impression techniques in a scenario of multi-implant system with different implant angulations and subgingival alignment levels
}

\author{
Martínez-Rus, Francisco ; García, Carmen ; Santamaría, Andrea ; Òzcan, Mutlu ; Pradíes, Guillermo
}

\begin{abstract}
PURPOSE: To evaluate the effect of various implant-level impression techniques on the accuracy of definitive casts for a multiple internal connection implant system with different implant angulations and subgingival depths. MATERIAL AND METHODS: Six tapered Screw-Vent implants were placed in a reference model with different angles (0,15, and 30 degrees) and subgingival positions (0, 1, and $3 \mathrm{~mm})$. Twenty mediumconsistency polyether impressions of this model were made with 4 techniques ( $\mathrm{n}=5$ per group): (1) indirect technique, (2) unsplinted direct technique, (3) acrylic resin-splinted direct technique, and (4) metal-splinted direct technique. Impressions were poured with type IV dental stone. The interimplant distances were measured for casts using a coordinate measuring machine and the deviations compared with the reference model were calculated. Data were analyzed using intraclass correlation coefficient, ANOVA and Bonferroni test $(\alpha=0.05)$. RESULTS: Four impression procedures showed significant differences $(\mathrm{P}=0.0001)$. Only group 4 casts showed no significant differences in comparison with the reference model $(\mathrm{P}=0.666)$ (ANOVA repeated measures). CONCLUSIONS: The impression procedure affected the accuracy of definitive casts. The metal-splinted direct technique produced the most accurate casts, followed by acrylic resin-splinted direct, indirect, and unsplinted direct techniques.
\end{abstract}

DOI: https://doi.org/10.1097/ID.0b013e3182920dc5

Posted at the Zurich Open Repository and Archive, University of Zurich

ZORA URL: https://doi.org/10.5167/uzh-89892

Journal Article

Accepted Version

Originally published at:

Martínez-Rus, Francisco; García, Carmen; Santamaría, Andrea; Ȯzcan, Mutlu; Pradíes, Guillermo (2013). Accuracy of definitive casts using 4 implant-level impression techniques in a scenario of multi-implant system with different implant angulations and subgingival alignment levels. Implant Dentistry, 22(3):268-276.

DOI: https://doi.org/10.1097/ID.0b013e3182920dc5 


\section{System: Effect of Implant Angulation and Subgingival Alignment Level}

AUTHORS: Francisco Martínez-Rus, DDS, $\mathrm{PhD}^{1}$, Carmen García, DDS, $\mathrm{PhD}^{2}$, Andrea Santamaría, DDS, $\mathrm{PhD}^{2}$, Mutlu Özcan, DDS, Dr Med Dent, $\mathrm{PhD}^{3}$, Guillermo Pradíes, DDS, $\mathrm{PhD}^{4}$

\section{ABSTRACT (199 words)}

Purpose To evaluate the effect of four implant-level impression techniques on the accuracy of definitive casts for a multiple internal connection implant system with different implant angulations and subgingival depths. Material and Methods: Six Tapered Screw-Vent implants were placed in a reference model with different angles $(0,15$, and 30 degrees $)$ and subgingival positions $(0,1$, and 3 $\mathrm{mm}$ ). Twenty medium-consistency polyether impressions of this model were made with four techniques ( $\mathrm{n}=5$ per group): (1) indirect-, (2) unsplinted direct-, (3) acrylic resin splinted direct-, and (4) metal splinted direct technique. Impressions were poured with type IV dental stone. The interimplant distances were measured for casts using a coordinate measuring machine and the deviations compared to the reference model were calculated. Data were analyzed using intraclass correlation coefficient, ANOVA and Bonferroni's Test $(\alpha=0.05)$. Results: Intra-technique reliability of measurements was excellent for all groups $(\mathrm{p}=0.0001)$. ANOVA showed significant differences among the four impression procedures $(\mathrm{p}=0.0001)$. Only the group 4 casts showed no significant differences in comparison with the reference model $(p=0.666)$. Conclusions: The impression procedure affected the accuracy of definitive casts. The metal splinted direct technique produced the most accurate casts, followed by acrylic resin splinted direct-, indirect-, and unsplinted directtechniques.

KEY WORDS: direct impression technique, indirect impression technique, internal connection implant, splinting procedure.

1 Associate Professor, Dept. of Buccofacial Prostheses, Faculty of Odontology, University Complutense of Madrid, Madrid, Spain.

${ }^{2}$ Lecturer, Dept. of Buccofacial Prostheses, Faculty of Odontology, University Complutense of Madrid, Madrid, Spain. 
${ }^{3}$ Professor, Head of Dental Materials Unit, University of Zürich, Center for Dental and Oral Medicine, Clinic for Fixed and Removable Prosthodontics and Dental Materials Science, Zurich, Switzerland.

${ }^{4}$ Professor, Associate Dean, Dept. of Buccofacial Prostheses, Faculty of Odontology, University Complutense of Madrid.

Reprint requests and correspondence to: Prof. Dr.med.dent. Mutlu Özcan, Ph.D, University of Zürich, Head of Dental Materials Unit, Center for Dental and Oral Medicine, Clinic for Fixed and Removable Prosthodontics and Dental Materials Science, Plattenstrasse 11, CH-8032, Zürich, Switzerland.

Tel: +41-44-6345600＜noBreak>Ｆax:+41-44-6344305Ｅmail: mutluozcan@hotmail.com 
Osseointegration has changed various aspects of restorative dentistry, leading to a significant improvement in the quality of life for edentulous patients. ${ }^{1-3}$ Osseointegrated implants used for oral rehabilitation present clinical success consistently supported by the literature and this type of therapy applies a considerable positive impact on the psychosocial condition of the patients. ${ }^{1-3}$

Osseointegrated implants are completely embedded in the bone and their interfaces are not resilient. Therefore, only minimal movements can be observed that are attributed to bone deformation under load. ${ }^{4-6}$ The stress generated by the absence of passive fit for implant supported fixed dental prostheses (FDP) does not dissipate over time due to the ankylotic nature of osseointegration, which may lead to mechanical and/or biologic complications, confirming the need for prosthetic precision to ensure longterm success. $^{7-9}$

Impression materials and techniques are fundamental in the precision of fit and passivity of implant supported FDPs. ${ }^{8,10,11}$ It is imperative for the impression to accurately register and transfer to the master cast the three-dimensional position of the osseointegrated implants. Two impression methods are commonly used in implantology, namely indirect and direct method. The indirect method uses tapered transfer copings and a closed tray. In this method, the transfers remains attached intraorally to the implants once the impression is removed after the elastomer material has been set. The copings are then removed from the mouth, connected to the analogues and carefully repositioned with the correct orientation back into the impression. Previous studies have shown that the precise replacement of the tapered transfers in their original position is difficult and can be influenced by the design of the transfer coping. ${ }^{12-15}$ Moreover, the weak union between the tapered coping and the impression material may facilitate the movement of the analogues due to the expansion of the dental stone during setting. ${ }^{14}$

The direct technique uses square transfer copings, connected to the implants with screws that project above the height of the copings and through openings in a customized impression tray. The screws are loosened when the elastomer material is set and the tray is removed from the mouth with the 
impression copings retained within the impression. The implant analogues are fastened to the impression copings using the same screws. Since the direct technique allows for the impression copings to remain in the impression, it reduces the deformation of the impression material upon recovery from the mouth, and removes the concern for replacing the coping back into its respective space in the impression. However, some disadvantages of this technique are that there are more parts to control when fastening, and there may be some rotational movement of the copings when securing the analogues, which may result in misfits between components. ${ }^{15,16}$

The splinted direct techniques use square transfer copings, connected to each other with a rigid material, in a customized open impression tray. Although different materials have been tested to splint impression copings, such as composite resin, impression plaster, and stainless steel pins; acrylic resin, alone or in combination with dental floss, is the material used most often to prevent individual coping movements during the impression-making procedure. ${ }^{10}$ However, according to Dumbrigue et al, ${ }^{17}$ relatively large amounts of acrylic resin used for connecting the copings could present significant polymerization shrinkage and consequent inaccuracy of the mold. Therefore, it is recommended that the segments connected with acrylic resin should be separated after resin polymerization, and then reconnected with a small amount of this material in order to relieve the stress and minimize adverse effects of polymerization shrinkage. ${ }^{18,19}$ The accuracy of a splinted impression technique depends upon its resistance to deformation under the forces of impression material. Thus, theoretically, a technique that uses a more rigid splint material would produce a more accurate master cast. ${ }^{20}$ Therefore, the rigidity and dimensional stability of a metal framework in combination with impression plaster might make it a good choice for splinting the impression copings.

Despite the fact that many authors have compared different impression materials and techniques, the findings have been extremely non-homogeneous. ${ }^{10}$ In some studies, splinting of square transfer copings improved the accuracy of the resulting casts. ${ }^{13,19,21-25}$ Among those studies, several showed that the splinting procedure was essential because unsplinted direct copings exhibited no more 
accuracy than indirect copings. ${ }^{13,19}$ However, others investigators found no improvement with splitting

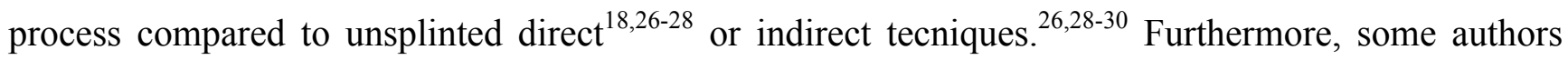
found that the indirect impression technique produced a more accurate master cast than pick-up impression techniques. ${ }^{26,30,31}$ Of the impression materials that have been investigated, polyether and addition-cured silicone (polyvinyl siloxane) resulted in the most accurate casts. ${ }^{11,24,28,32-34}$

The previously referenced studies have generally used experimental designs in which all of the implants were placed parallel to each other and at the same apico-coronal level. In some clinical instances, however, there is a need to place the implant angulated and/or more subgingivally due to bone availability and/or aesthetic considerations. The lack of parallelism between implants may result in increased distortion of impression material during removal from the mouth that may generate an inaccurate model. ${ }^{11,24,35-39}$ Furthermore, when an implant is placed subgingivally, there is a decrease in the portion of the coping which is supragingivally exposed. This reduction in the surface of the impression coping that can be effectively impressed may lessen the stability of the impression coping in the impression material and, therefore, affect the accuracy of the impression. ${ }^{40}$ In addition, the effect of both implant angulation and subgingival depth might be heightened by an increasing number of implants.

Although earlier published studies on this topic analyzed impressions of implants with external hexagonal implant-abutment configurations, recent investigations have evaluated the accuracy of impressions with implants exhibiting internal implant-abutment connections..$^{13,24,25,36-40}$ The likelihood of deformation in the impression appeared to be higher for internal connection implants than for external connection implants as a result of the dislodgement of more impression material when the impression tray is removed from the mouth. ${ }^{36}$ Moreover, the accuracy of impressions for internal connection implants decreased as the divergence angle between implants increased. ${ }^{24,39}$ However, there are no data about the effect of implant-level impression technique on the accuracy of definitive 
casts for a multiple internal connection implant system with different implant angulations and subgingival depths.

The objective of this study was to compare the dimensional accuracy of definitive casts obtained from four different impression techniques (indirect-, direct-, acrylic resin splinted direct-, and metal splinted direct-technique) of six internal connection implants placed with different angles and subgingival depths in a partially edentulous upper-jaw model. The null hypothesis tested was the impression technique would have no effect on the accuracy of the resulting casts compared to the reference model.

\section{MATERIAL AND METHOD}

\section{Fabrication of the Reference Model}

Six internal connection dental implants (Tapered Screw-Vent, $3.75 \mathrm{~mm}$ diameter and $11.5 \mathrm{~mm}$ long; Zimmer Dental, Carlsbad, California, USA) were placed in a commercially available partially edentulous maxilla model with a 3-mm-thick artificial mucosa (M310; Implant Bone, Buenos Aires, Argentina). The implants were placed with different angles (0, 15, and 30 degrees) and subgingival depths $(0,1$, and $3 \mathrm{~mm})$ in FDI-positions $17,15,12,22,24$, and 26, simulating a common clinical situation. The distribution of implant positions is shown in Table 1. The convergence angle between implants was controlled using a metallic guide (All-on-4 Guide; Nobel Biocare, Göteborg, Sweden) and a goniometer (SH-117; Twister Medical, Barcelona, Spain), whereas the subgingival depth was verified with a 1-mm incremental periodontal probe (UNC 15; Hu-Friedy, Chicago, Illinois, USA).

\section{Impression Procedures}

Four different groups of impression techniques were investigated ( $\mathrm{n}=5$ per group). To standardize the impression procedures, all impressions of the reference model were made with polypropylene stock trays (Position Trays, Ref. 71601; 3M ESPE, Seefeld, Germany) and using the same type of impression coping (Ref. FMT3; Zimmer Dental), which allows the use of both indirect and direct 
methods, depending on the length of its retaining screw. To allow access to the transfer coping screw, the trays were perforated for the direct techniques in the implant locations.

In the first group, an indirect method was performed with impression copings connected to the implants by short screws (Ref. URS2; Zimmer Dental) (Fig 1a), and the screw cavities filled with cotton tape and provisional restorative material (Fermit N; Ivoclar Vivadent, Schaan, Liechtenstein). In the second group, a direct technique was used with unsplinted impression copings connected to the implants by long screws (Ref. DHTS; Zimmer Dental) (Fig 1b). In the third group, the procedure was similar to that of the previous group, except that the impression copings were tied up with 4 complete loops of dental floss and splinted with autopolymerizing acrylic resin (Duralay; Reliance Dental, Alsip, Illinois, USA) before impression (Fig 1c). Acrylic resin was applied around the impression copings using an incremental application technique with a brush. The amount of acrylic resin was assumed to be satisfactory when the square surfaces of the transfer copings were fully covered with a layer about $2 \mathrm{~mm}$ in thickness. After 17 minutes, the splint was sectioned and readapted using the same acrylic resin in a brush bread method. Another 17-minute interval was allowed after additional splinting to reduce the effects of polymerization shrinkage. And in the fourth group, the impression copings were first splinted with a metal framework in combination with impression plaster (Fig 1d). On a preliminary cast produced by indirect technique, a rigid splint was made by joining metal cylinders around the transfers, leaving sufficient space around them. After positioning of the resulting framework in the reference model, impression plaster (Snow-White Plaster no. 2; Kerr, Orange, California, USA) was injected into the cylinders around each impression coping with a 5-cc plastic disposable syringe to secure the transfers to the metal framework. After the plaster had set (15 minutes), a direct technique was performed according to the previously mentioned procedure.

Regular-viscosity polyether impression material (Impregum Penta; 3M ESPE) was used for all impression procedures. An automix machine (Pentamix 3; 3M ESPE) was used to standardize all mixtures. The appropriate adhesive (Polyether adhesive; 3M ESPE) was applied to the stock trays. All 
copings were connected to the implants using a manual torque controller (Ref. 001457; GT Medical, Madrid, Spain) at $10 \mathrm{Ncm}$. Polyether was placed inside the tray and injected around the copings using a dispenser (Penta Elastomer syringe; 3M ESPE). The tray was seated over the reference model with finger pressure. After the impression material had polymerized (10 minutes from the start of mixing), the tray was removed. Impressions were inspected and repeated when any inaccuracies were found such as air voids, impression material between the analogue-impression coping interface, or impression material separation from the tray. Special care was taken to ensure that all components were properly oriented and completely seated. The same operator attached analogues to the impression copings using $10 \mathrm{Ncm}$ of torque. For the direct impression technique, the replicas were held with a haemostatic forceps to prevent the square coping from rotating inside the impression. This procedure is not necessary for the splinted direct techniques, but it was performed to standardize the methodology. For the indirect impression technique, the copings connected to their analogues were replaced in their corresponding holes.

Each impression was poured with vacuum-mixed type IV dental stone (Fujirock EP; GC, Tokyo, Japan) in accordance with the manufacturers' instructions to obtain the corresponding model. Casts were separated from the impressions after allowing the stone to set for 1 hour, followed by trimming and labeling to prepare for measurements. All impression steps and specimen fabrication were carried out at temperature ranging from $23^{\circ} \mathrm{C}$ to $25^{\circ} \mathrm{C}$.

\section{Assessment Accuracy}

A coordinate measuring machine (CMM) (Contura G2; Carl Zeiss, Oberkochen, Germany) with a mechanical probe of $0.5 \mathrm{~mm}$ diameter was used to record three-dimensional (3D) coordinates of the centers of the implant platforms on the reference model and of their analogues on the resulting casts (Fig 2). To easily locate the center point of each implant platform by direct touching, short screws (Ref. URS2; Zimmer Dental) were connected to the implants and their replicas with a torque of 10 $\mathrm{Ncm}$. The machine read the input from the touch probe and simultaneously sent the $\mathrm{X}-\mathrm{Y}-\mathrm{Z}$ coordinate 
information to a measuring software (Calypso CAD-Based Software; Carl Zeiss), which transformed the 3D data into distances between the implants using the Euclidean distance formula (Fig 3). The center-to-center distances between the 6 implants were measured 5 times for the reference model and for each of the 20 resulting casts. The values were recorded in a spreadsheet (Microsoft Excel 2010; Microsoft Corp, Redmond, Washington, USA).

\section{Statistical analysis}

Statistical analysis was performed using SPSS Statistics Version 19 software (IBM, Armonk, NY, USA). The Kolgoromov-Smirnov test was used to confirm that the data were normally distributed. The intra-technique reliability was analyzed using intraclass correlation coefficients (ICC). The intertechnique variability was analyzed using analysis of variance (ANOVA) with repeated measures followed by Bonferroni's post hoc test. $\mathrm{P}$ values less than 0.05 were considered to be statistically significant in all tests.

\section{RESULTS}

Intra-technique reliability of measurements was excellent for all groups $(p=0.0001)$ (Table 2$)$. The ICC values revealed a high degree of reproducibility within each impression method. Inter-technique variability was evaluated by comparing the center-to-center distances obtained from the reference model with those from the casts produced by the four impression techniques (Table 3). The distortion value was determined as the absolute value of the difference in micrometers $(\mu \mathrm{m})$ between the measurement of the reference model and the corresponding cast. The results of the mean distortions are shown in Fig 4.

Repeated-measures ANOVA showed significant differences among the four impression procedures $(p=0.0001)$ (Table 4). Post-hoc pairwise comparisons with Bonferroni correction found significant differences with respect to the reference model for group $1(p=0.0001)$, group $2(p=0.0001)$, and group 
$3(p=0.014)$ casts. Only the group 4 casts showed no significant differences in comparison with the reference model $(\mathrm{p}=0.666)$. However, no significant differences were found between the group 1 and the group $2(p=1.000)$ or between the group 3 and the group $4(p=1.000)$.

\section{DISCUSSION}

An impression procedure that precisely registers and transfers to the master cast the three-dimensional position of the osseointegrated implants is the first step for achieving ideal fit of implant-supported FDPs. ${ }^{8,10,11}$ Generally, the abutment-level impression technique has been the favoured technique for internal connection implant systems. However, selection of abutments can be difficult under conditions of extensive rehabilitation where vertical space or angulation of implants is inappropriate. Laboratory evaluation of the master cast produced from an implant-level impression facilitates the selection and correction of abutments and prostheses. ${ }^{37}$ Because of this, the implant-level impression technique is indispensable for a multiple internal connection implant system. This study evaluated the dimensional accuracy of definitive casts obtained from four different impression techniques (indirect-, direct-, acrylic resin splinted direct-, and metal splinted direct-technique) of six internal connection implants placed with different angles and subgingival depths in a partially edentulous model. The results showed significant differences among the four impression procedures. In comparison with the reference model, the casts produced by the unsplinted direct technique recorded the highest distortion $(172.42 \mu \mathrm{m})$ followed by those obtained from the indirect- $(158.38 \mu \mathrm{m})$, acrylic resin splinted direct$(84.30 \mu \mathrm{m})$, and metal splinted direct-technique $(38.73 \mu \mathrm{m})$, which was the most accurate method. Thus, the null hypothesis that the accuracy of master casts would not be affected by the impression technique was rejected.

Although the accuracy of the implant impression techniques is a topic that has been widely studied in the literature ${ }^{10-40}$, no consensus has been reached. With respect to the comparison of indirect versus unsplinted direct techniques, the present study showed none of the two procedures to be superior. 
These results are in agreement with those reported by other authors. ${ }^{13,16,19,28,34}$ In the direct method, the maintenance of transfer copings in the impression would be an advantage, as this procedure avoids replacement of the copings in the impression. ${ }^{12-14}$ However, some authors found greater accuracy using the indirect technique. ${ }^{26,30,31}$ They stated that the torque necessary to fasten square copings on analogues in the direct technique creates more distortion that any inaccuracy derived from replacement of the copings. This could explain why both techniques yielded comparable results in the current investigation.

This study showed that the splinted direct techniques reproduced the three-dimensional position of implants more accurately than the indirect and unsplinted direct techniques. These results agree with previous investigations that emphasized the splinting of impression copings. ${ }^{13,19,21-25}$ The time required for impression making is considerably longer with the splinting methods compared to the nonsplinting methods. However, the splinting procedures have been recommended for maintaining a more precise inter-implant relationship, avoiding rotation of impression copings in the impression during fastening the implant analogue, which is one of the drawbacks of the direct impression method. ${ }^{15} \mathrm{~A}$ systematic review on the accuracy of implant impressions on abutment or internal connection implant level revealed that more studies reported greater accuracy with the splinting technique versus the nonsplinting one. ${ }^{10}$ Nonetheless, controversial results exists in the dental literature regarding whether or not to splint, as some studies found no improvement with splitting process compared to unsplinted direct $^{18,26-28}$ or indirect methods. ${ }^{26,28-31}$ Splint material type could be responsible from the reported variations between studies. Although this investigation showed no statistically significant differences between both splitting procedures, the mean distortion measured for casts produced by the metal splinted direct technique $(38.73 \mu \mathrm{m})$ was lower than that observed for those obtained from the acrylic resin splinted direct technique $(84.30 \mu \mathrm{m})$. This may be explained by the differences in the dimensional stability of splint materials. ${ }^{20}$ Acrylic resin is the material used most often for splinting the impression copings. ${ }^{10}$ To minimize adverse effects of polymerization shrinkage, it is recommended that the acrylic resin splint should be separated after polymerization, and then reconnected with a 
small amount of this material. ${ }^{18,19}$ According to Mojon et al ${ }^{41}$ that demonstrated that $80 \%$ of the acrylic resin shrinkage occurs in the first 17 minutes, in the present study, the separation and reconnection was performed after this time interval in order to relieve the shrinkage stress. Nevertheless, the high rigidity of a metal framework in combination with impression plaster resists better the potential forces of distortion, increasing the accuracy of the working cast. There seems to be a clinical advantage in splinting the square copings with a metal framework and impression plaster to avoid problems related to resin polymerization shrinkage. Therefore, there is improved efficiency and greater transfer precision as a result of splitting stability.

Angulated and/or deep subgingival implants is a common clinical problem because of anatomic limitations and aesthetic considerations. Several authors have tested situations in which the implants were placed with different angles or subgingival depths, yielding varying results. ${ }^{11,16,24,35-40}$ Some investigations showed less accurate impressions with angulated implants than with straight implants for experimental models with multiple implants. ${ }^{11,24,35,38}$ Among those studies, splinting of square transfer copings with acrylic resin improved the precision of the resulting casts. ${ }^{24,38}$ Others authors reported no angulation effect on the accuracy of impressions for two or three nonparallel implants with up to 15 degrees of angulation. ${ }^{16,36,39}$ However, Lee et $\mathrm{al}^{37}$ found that the unsplinted and splinted direct techniques produced more accurate master casts than indirect one for two internal connection implants angulated 10 degrees. With respect to the subgingival depth, Lee et $\mathrm{al}^{40}$ showed that there was no effect on the dimensional accuracy of putty and light-body combination polyvinyl siloxane impressions, either vertically or horizontally. For medium-body polyether impressions, the deeper implants exhibited a significantly less accurate impression horizontally. However, this implant depth effect could be compensated for by using an extension of the impression coping. ${ }^{40}$ In the present investigation, six internal hex connection implants were placed with different angles $(0,15$, and 30 degrees) and subgingival depths $(0,1$, and $3 \mathrm{~mm})$, correlating to the anatomic conditions of an edentulous maxilla. Currently, it is known that the internal connection implants give rise to different considerations than external connection implants with regard to impression procedures. The greater 
contact area between impression copings and internal connection implants may increase the distortion of the impression as a result of the dislodgement of more impression material when removing the impression tray from the mouth. ${ }^{36}$ In this study, this effect may be heightened by using multiple implants placed with different angles and depths. In this regard, the metal splinted direct-technique was the most accurate method to register and transfer to the working cast the three-dimensional position of implants. It is hypothesized that the excellent rigidity and dimensional stability of metal framework in combination with impression plaster played a role in providing additional retention and resistance against the coping movements during the impression-making procedure.

The contradictory results for implant transfer accuracy that have been reported in the literature may be partially explained by the use of different evaluation methods. Standardized test variables for impression techniques and quantitative measurements are necessary to facilitate study comparisons and improve impression precision. ${ }^{37}$ In previous studies, a number of different methodologies were used to assess the accuracy of fabricated master casts. Most investigations evaluated the positional changes of implant analogues by measuring inter-implant distances or distances from the reference plane with a coordinate measuring machine, as was done in the present study, or by measuring interimplant angles or distances with a profile projector. ${ }^{13,15,16,23,24-28,32-35,39}$ Several authors used electrical resistance strain gauges for measuring the stress introduced in a metal framework connected to the abutments of the respective working cast. ${ }^{18,19,22,36}$ Although strain gauges enable the measurement of deformation in multiple directions, may not be accurate when there are angulations between implants. ${ }^{36}$ Another difficulty of this method is the fabrication of the "neutral" reference model. Even when it is fabricated with the framework already completed and attached to the abutment-implant complex, residual stresses were measured when the framework again connected to the reference model. ${ }^{18,19}$ Furthermore, it is difficult to relate the measured strain values to clinical parameters. Some experiments used microscopy to measure the marginal gap width between a metal framework and the abutments of the respective working cast at selected points..$^{14,20,37,39}$ However, since inaccuracy is expressed in only one dimension, information is lost. 
This study was designed to investigate the dimensional accuracy of definitive casts obtained from four different implant impression techniques. The methodology was standardized to allow a careful evaluation of different procedures, isolating variables associated with laboratory processes. This standardization included use of the same type of stock tray, impression material, impression coping, and a reliable measurement method. Nevertheless, errors may be introduced during any of the several steps required to make an implant master cast, such as dimensional changes of the impression material, inaccurate repositioning of impression copings, improper connection of components and dimensional changes of the stone used to fabricate the master cast. The authors made an effort to minimize these possible errors as evidenced by the high degree of reproducibility within each impression method $(\mathrm{ICC}=1)$. A possible source of error was the fit of the individual impression copings to the implants or implant analogues. Many factors contribute to intimacy of fit of implant and prosthetic components. Manufacturing variables include machining tolerances of implant components, materials used in the manufacturing process, and the resultant physical and mechanical properties of the components. The machining tolerance of implant components is considered to be the most intimate fit that can be achieved. Several authors reported the implant component tolerances ranged from $22 \mu \mathrm{m}$ to $100 \mu \mathrm{m} .{ }^{42-}$ 44 Therefore, when the results of the studies investigating the implant impression accuracy are interpreted, the machining tolerance should be considered as one of the factors affecting accuracy. ${ }^{10}$

A possible limitation of the present study was that the measured distortion values did not completely describe the three-dimensional changes that occurred in the implant definitive casts. For example, this design could not detect the presence and the amount, if it existed, of axial rotation of the analogues caused by the impression technique. Although the present investigation did not simulate all clinical conditions, the techniques evaluated are expected to produce similar results in the oral environment. Future studies, particularly long-term prospective clinical trials, are needed to make further refinements to the impression and laboratory procedures, to determine the amount of distortion tolerable biologically and mechanically, and to clinically analyze failures and complications in 
implant-supported prostheses. In addition, the precision of the digital implant impressions should be evaluated in further investigations.

\section{CONCLUSION}

Based on the results of this study, the impression technique affected the accuracy of implant master casts. The metal splinted direct technique was the most accurate impression procedure for multiple internal connection implants placed with different angles and depths, followed by acrylic resin splinted direct-, indirect-, and unsplinted direct-techniques. There was no statically significant difference in accuracy between both splitting methods or between the indirect and unsplinted direct techniques.

\section{ACKNOWLEDGMENTS}

The authors gratefully acknowledge Centre of Data Processing, Computing Service for Research Support of University Complutense of Madrid, Madrid, Spain, for the assistance with the statistical analysis. Furthermore, the authors thank the company Zimmer Dental for the support of the study with implants, transfer copings, and implant replicas.

\section{DISCLOSURE:}

The authors claim to have no commercial associations (eg, consultancies, patent-licensing arrangements, equity interests) that might represent a conflict of interest in connection with the submitted manuscript. 


\section{REFERENCES}

1. Pjetursson BE, Lang NP. Prosthetic treatment planning on the basis of scientific evidence. J Oral Rehabil. 2008;35:72-79.

2. Emami E, Heydecke G, Rompré PH, et al. Impact of implant support for mandibular dentures on satisfaction, oral and general health-related quality of life: a meta-analysis of randomizedcontrolled trials. Clin Oral Implants Res. 2009;20:533-544.

3. Brennan M, Houston F, O'Sullivan M, et al. Patient satisfaction and oral health-related quality of life outcomes of implant overdentures and fixed complete dentures. Int J Oral Maxillofac Implants. 2010;25:791-800.

4. Sahin S, Cehreli MC, Yalcin E. The influence of functional forces on the biomechanics of implant-supported prostheses-a review. J Dent. 2002;30:271-282.

5. Cehreli MC, Akkocaoglu M, Comert A, et al. Human ex vivo bone tissue strains around natural teeth vs. immediate oral implants. Clin Oral Implants Res. 2005;16:540-548.

6. Juodzbalys G, Kubilius R, Eidukynas V, et al. Stress distribution in bone: single-unit implant prostheses veneered with porcelain or a new composite material. Implant Dent. 2005;14:166-175.

7. Guichet DL, Caputto A, Choi H, et al. Passivity of fit and marginal opening in screw or cementretained implant fixed partial denture designs. Int J Oral Maxillofac Implants. 2000;15:239-246.

8. Sahin S, Cehreli MC. The significance of passive framework fit in implant prosthodontics: current status. Implant Dent. 2001;10:85-92.

9. Karl M, Taylor TD, Wichmann MG, et al. In vivo stress behaviour in cemented and screwretained five-unit implant FPDs. J Prosthodont. 2006;15:20-24.

10. Lee H, So JS, Hochstedler JL, et al. The accuracy of implant impressions: a systematic review. $J$ Prosthet Dent. 2008;100:285-291.

11. Sorrentino R, Gherlone EF, Calesini G, et al. Effect of implant angulation, connection length, and impression material on the dimensional accuracy of implant impressions: an in vitro comparative study. Clin Implant Dent Relat Res. 2010;12:63-76. 
12. Liou AD, Nicholls JI, Yuodelis RA, et al. Accuracy of replacing three tapered transfer impression copings in two elastomeric impression materials. Int J Prosthodont. 1993;6:377-383.

13. Cabral LM, Guedes CG. Comparative analysis of 4 impression techniques for implants. Implant Dent. 2007;16:187-194.

14. Del'Acqua MA, Chávez AM, Compagnoni MA, et al. Accuracy of impression techniques for an implant-supported prosthesis. Int J Oral Maxillofac Implants. 2010;25:715-721.

15. Hariharan R, Shankar C, Rajan M, et al. Evaluation of accuracy of multiple dental implant impressions using various splinting materials. Int J Oral Maxillofac Implants. 2010;25:38-44.

16. Conrad HJ, Pesun IJ, DeLong R, et al. Accuracy of two impression techniques with angulated implants. J Prosthet Dent. 2007;97:349-356.

17. Dumbrigue HB, Gurun DC, Javid NS. Prefabricated acrylic resin bars for splinting implant transfer copings. J Prosthet Dent. 2000;84:108-110.

18. Inturregui JA, Aquilino SA, Ryther JS, et al. Evaluation of three impression techniques for osseointegrated oral implants. J Prosthet Dent. 1993;69:503-509.

19. Naconecy MM, Teixeira ER, Shinkai RS, et al. Evaluation of the accuracy of 3 transfer techniques for implant-supported prostheses with multiple abutments. Int J Oral Maxillofac Implants. 2004;19:192-198.

20. Del Acqua MA, Chavez AM, Castanharo SM, et al. The effect of splint material rigidity in implant impression techniques. Int J Oral Maxillofac Implants. 2010;25:1153-1158.

21. Assif D, Fenton A, Zarb G, et al. Comparative accuracy of implant impression procedures. Int $J$ Periodontics Restorative Dent. 1992;12:112-121.

22. Assif D, Marshak B, Schmidt A. Accuracy of implant impression techniques. Int J Oral Maxillofac Implants. 1996;11:216-222.

23. Vigolo P, Majzoub Z, Cordioli G. Evaluation of the accuracy of three techniques used for multiple implant abutment impressions. J Prosthet Dent. 2003;89:186-192.

24. Assuncao WG, Filho HG, Zaniquelli O. Evaluation of transfer impressions for osseointegrated implants at various angulations. Implant Dent. 2004;13:358-366. 
25. Vigolo P, Fonzi F, Majzoub Z, et al. An evaluation of impression techniques for multiple internal connection implant prostheses. J Prosthet Dent. 2004;92:470-476.

26. Humphries RM, Yaman P, Bloem TJ. The accuracy of implant master casts constructed from transfer impressions. Int J Oral Maxillofac Implants. 1990;5:331-336.

27. Hsu CC, Millstein PL, Stein RS. A comparative analysis of the accuracy of implant transfer techniques. J Prosthet Dent. 1993;69:588-593.

28. Herbst D, Nel JC, Driessen $\mathrm{CH}$, et al. Evaluation of impression accuracy for osseointegrated implant supported superstructures. J Prosthet Dent. 2000;83:555-561.

29. Spector MR, Donovan TE, Nicholls JI. An evaluation of impression techniques for osseointegrated implants. J Prosthet Dent. 1990;63:444-447.

30. Burawi G, Houston F, Byrne D, et al. A comparison of the dimensional accuracy of the splinted and unsplinted impression techniques for the Bone-Lock implant system. J Prosthet Dent. 1997;77:68-75.

31. De La Cruz JE, Funkenbusch PD, Ercoli C, et al. Verification jig for implant-supported prostheses: A comparison of standard impressions with verification jigs made of different materials. J Prosthet Dent. 2002;88:329-336.

32. Lorenzoni M, Pertl C, Penkner K, et al. Comparison of the transfer precision of three different impression materials in combination with transfer caps for the Frialit-2 system. J Oral Rehabil. 2000;27:629-638.

33. Wee AG. Comparison of impression materials for direct multi-implant impressions. J Prosthet Dent. 2000;83:323-331.

34. Wenz HJ, Reuter HU, Hertrampf K. Accuracy of impressions and casts using different implant impression techniques in a multi-implant system with an internal hex connection. Int $J$ Oral Maxillofac Implants. 2008;23:39-47.

35. Carr AB. Comparison of impression techniques for a five-implant mandibular model. Int J Oral Maxillofac Implants. 1991;6:448-455. 
36. Choi JH, Lim YJ, Yim SH, et al. Evaluation of the accuracy of implant-level impression techniques for internal-connection implant prostheses in parallel and divergent models. Int J Oral Maxillofac Implants. 2007;22:761-768.

37. Lee YJ, Heo SJ, Koak JY, et al. Accuracy of different impression techniques for internalconnection implants. Int J Oral Maxillofac Implants. 2009;24:823-830.

38. Assuncao WG, Britto RC, Ricardo Barao VA, et al. Evaluation of impression accuracy for implant at various angulations. Implant Dent. 2010;19:167-174.

39. Jang HK, Kim S, Shim JS, et al. Accuracy of impressions for internal-connection implant prostheses with various divergent angles. Int J Oral Maxillofac Implants. 2011;26:1011-1015.

40. Lee H, Ercoli C, Funkenbusch PD, et al. Effect of subgingival depth of implant placement on the dimensional accuracy of the implant impression: an in vitro study. J Prosthet Dent. 2008;99:107113.

41. Mojon P, Oberholzer JP, Meyer JM, et al. Polymerization shrinkage of index and pattern acrylic resins. J Prosthet Dent. 1990;64:684-688.

42. Ma T, Nicholls JI, Rubenstein JE. Tolerance measurements of various implant components. Int J Oral Maxillofac Implants. 1997;12:371-375.

43. Rubenstein JE, Ma T. Comparison of interface relationships between implant components for laser-welded titanium frameworks and standard cast frameworks. Int J Oral Maxillofac Implants. 1999;14:491-495.

44. Kim S, Nicholls JI, Han $\mathrm{CH}$, et al. Displacement of implant components from impressions to definitive casts. Int J Oral Maxillofac Implants. 2006;21:747-755. 


\section{LEGENDS}

Table 1 Distribution of implant positions.

Table 2 Results of intraclass correlation coefficient (ICC) analyses.

Table 3 Mean (standard deviation-SD) values of the inter-implant distances ( $\mathrm{mm})$ measured on reference model and definitive casts $(n=5)$.

Table 4 Results of one-way analysis of variance with repeated measures (alpha $=0.05$ ).

Fig. 1 Reference model with: a) transfer copings connected to the implants for indirect impression technique, b) transfer copings connected to the implants for unsplinted direct impression technique, c) transfer copings splinted with dental floss and autopolymerizing acrylic resin, and d) transfer copings splinted with a metal framework in combination with impression plaster.

Fig. 2 Measuring machine used to record the X-Y-Z coordinate information of the center point of each implant platform by direct touching.

Fig. 3 Schematic representation of the 15 inter-implant distances, which were calculated using the Euclidean norm.

Fig. 4 Mean distortion $(\mu \mathrm{m})$ and standard deviation of all experimental groups. 


\section{TABLES}

Table 1 Distribution of implant positions.

\begin{tabular}{cccc} 
Implant Number & FDI-Position & Convergence Angles & Subgingival Depths \\
$\mathbf{1}$ & 12 & Straight & 3 millimetres \\
$\mathbf{2}$ & 22 & Straight & 3 millimetres \\
$\mathbf{3}$ & 15 & 15 degrees & 1 millimetre \\
$\mathbf{4}$ & 24 & 15 degrees & 1 millimetre \\
$\mathbf{5}$ & 17 & 30 degrees & Flush \\
$\mathbf{6}$ & 26 & 30 degrees & Flush \\
\hline
\end{tabular}

Table 2 Results of intraclass correlation coefficient (ICC) analyses.

\begin{tabular}{lccc} 
Experimental Group & ICC & $\begin{array}{c}\mathbf{9 5 \%} \text { Confidence } \\
\text { Interval }\end{array}$ & P \\
\hline Group 1 (Indirect Technique) & 1 & $0.999-1$ & 0.0001 \\
Group 2 (Unsplinted Direct Technique) & 1 & $0.999-1$ & 0.0001 \\
Group 3 (Acrilic Resin Splinted Direct Technique) & 1 & $0.999-1$ & 0.0001 \\
Group 4 (Metal Splinted Direct Technique) & 1 & $0.999-1$ & 0.0001 \\
\hline
\end{tabular}


Table 3 Mean (standard deviation-SD) values of the inter-implant distances $(\mathrm{mm})$ measured on reference model and definitive casts $(n=5)$.

\begin{tabular}{cccccc}
$\begin{array}{c}\text { Inter-Implant } \\
\text { Distance }\end{array}$ & $\begin{array}{c}\text { Reference } \\
\text { Model }\end{array}$ & Group 1 & Group 2 & Group 3 & Group 4 \\
\hline d (1-2) & 17.82 & $17.97(0.17)$ & $17.95(0.12)$ & $17.85(0.20)$ & $17.91(0.10)$ \\
d (1-3) & 13.25 & $13.47(0.13)$ & $13.46(0.14)$ & $13.25(0.15)$ & $13.32(0.25)$ \\
d (1-4) & 25.76 & $25.78(0.10)$ & $25.82(0.07)$ & $25.48(0.17)$ & $25.79(0.15)$ \\
d (1-5) & 19.35 & $19.18(0.22)$ & $19.44(0.33)$ & $19.17(0.30)$ & $19.12(0.19)$ \\
d (1-6) & 32.25 & $32.29(0.18)$ & $32.40(0.22)$ & $32.04(0.17)$ & $32.17(0.09)$ \\
d (2-3) & 28.45 & $28.73(0.30)$ & $28.72(0.22)$ & $28.47(0.15)$ & $28.52(0.19)$ \\
d (2-4) & 9.33 & $9.42(0.19)$ & $9.48(0.41)$ & $9.39(0.34)$ & $9.22(0.10)$ \\
d (2-5) & 35.40 & $35.81(0.30)$ & $35.78(0.07)$ & $35.47(0.16)$ & $35.43(0.18)$ \\
d (2-6) & 20.49 & $20.92(0.16)$ & $20.84(0.05)$ & $20.47(0.28)$ & $20.51(0.15)$ \\
d (3-4) & 33.50 & $33.68(0.23)$ & $33.64(0.13)$ & $33.26(0.20)$ & $33.43(0.14)$ \\
d (3-5) & 11.26 & $11.46(0.18)$ & $11.38(0.11)$ & $11.20(0.20)$ & $11.16(0.29)$ \\
d (3-6) & 37.60 & $37.96(0.32)$ & $37.86(0.07)$ & $37.52(0.22)$ & $37.55(0.20)$ \\
d (4-5) & 37.17 & $37.31(0.11)$ & $37.31(0.12)$ & $36.97(0.28)$ & $37.09(0.08)$ \\
d (4-6) & 10.50 & $10.28(0.26)$ & $10.43(0.16)$ & $10.21(0.25)$ & $10.34(0.17)$ \\
d (5-6) & 38.62 & $38.88(0.20)$ & $38.82(0.12)$ & $38.58(0.40)$ & $38.61(0.14)$ \\
\hline
\end{tabular}

Table 4 Results of one-way analysis of variance with repeated measures (alpha=0.05).

\begin{tabular}{l|ccccc}
\multicolumn{1}{c|}{ Effect } & df & Sum of squares & Mean square & F & $\mathbf{P}$ \\
\hline Impression Techniques & 4 & 4.117 & 1.029 & 33.652 & 0.0001 \\
Residue & 296 & 9.054 & 0.031 & & \\
\hline
\end{tabular}




\section{FIGURES}
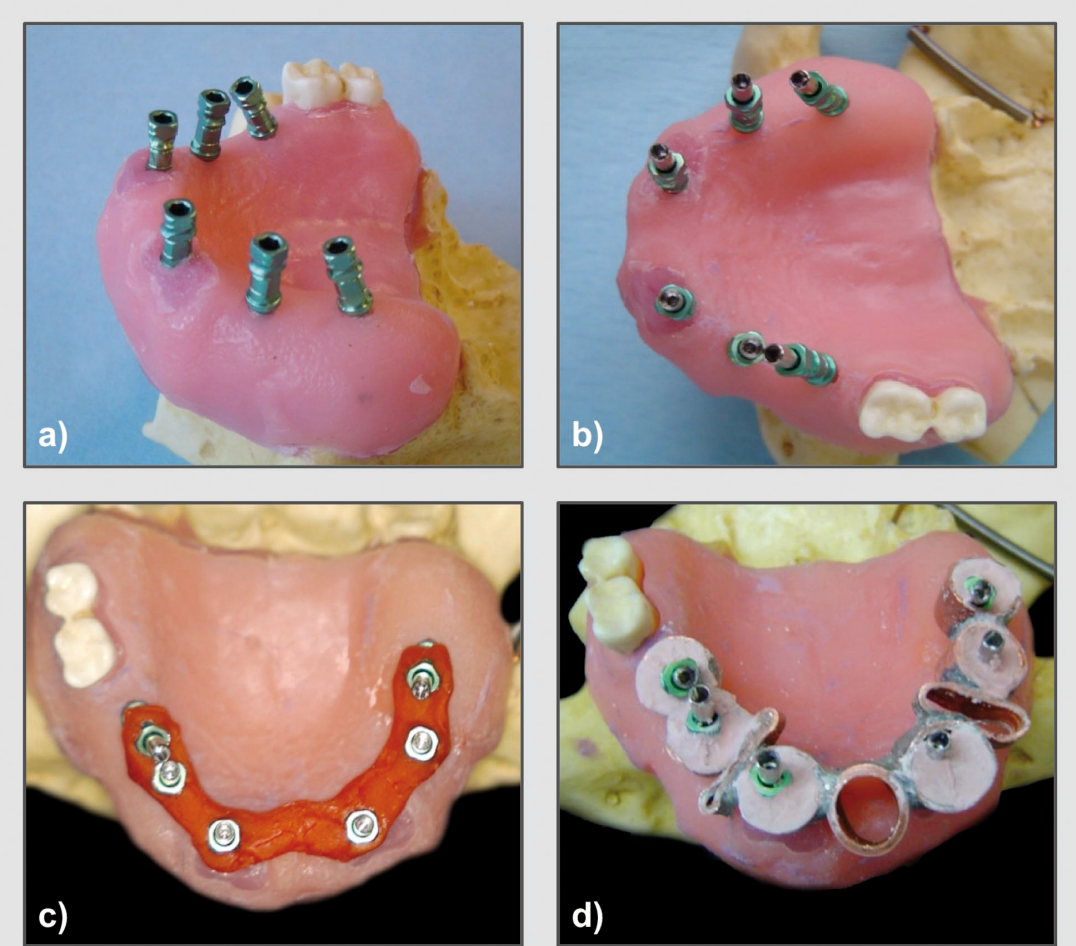

Fig. 1 Reference model with: a) transfer copings connected to the implants for indirect impression technique, b) transfer copings connected to the implants for unsplinted direct impression technique, c) transfer copings splinted with dental floss and autopolymerizing acrylic resin, and d) transfer copings splinted with a metal framework in combination with impression plaster.

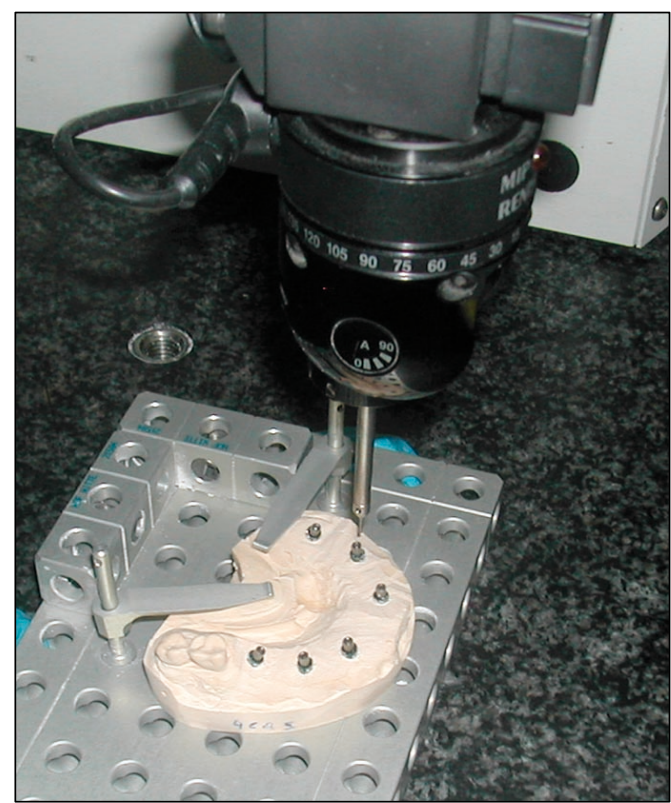

Fig. 2 Measuring machine used to record the $X-Y-Z$ coordinate information of the center point of each implant platform by direct touching. 


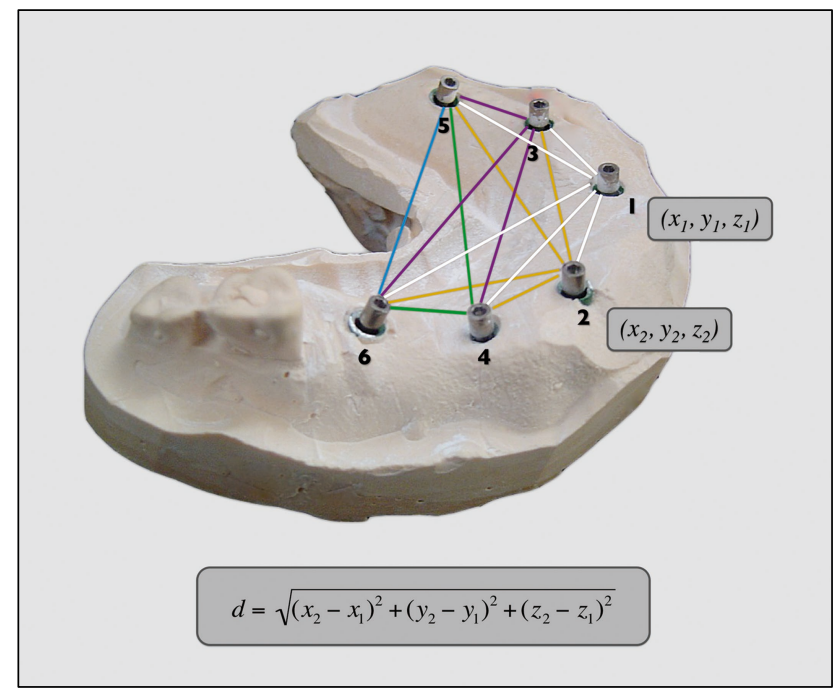

